\title{
Surgical treatment of rectovaginal endometriosis with rectal involvement
}

\author{
Vicente Payá • Juan José Hidalgo-Mora • \\ Cesar Diaz-Garcia • Antonio Pellicer
}

Received: 6 December 2010 / Accepted: 26 January 2011 / Published online: 12 February 2011

(C) Springer-Verlag 2011

\begin{abstract}
Rectovaginal endometriosis (RVE) is one of the most serious and incapacitating forms of presentation of this disease. Traditionally, medical treatment has not been considered effective for the majority of patients, being surgery the only reasonable and therapeutic choice in these cases. This exposes patients to a potentially serious morbidity, thus a careful evaluation should be done by a surgical board considering the impact of the disease as well as the quality of life of the patients. The main surgical techniques used are the shaving of the rectal wall affected by the endometriosic implants, the discoid excision of the front rectal wall, and the segmental intestinal resection, and there is no consensus concerning which is the most effective and suitable between them. The bibliography published in the last 10 years relating to the surgical treatment of RVE is being reviewed with the intention of updating the knowledge base about the topic and looking for common ground between different studies, allowing us to come closer to reaching a consensus about treatment for this pathology.
\end{abstract}

Keywords Deep endometriosis · Deeply infiltrating endometriosis · Laparoscopy · Rectovaginal endometriosis . Surgery Surgical management

V. Payá · J. J. Hidalgo-Mora $(\bowtie) \cdot$ C. Diaz-Garcia $\cdot$ A. Pellicer Department of Gynecology and Human Reproduction, La Fe University Hospital,

Bulevar Sur,

46026 Valencia, Spain

e-mail: hidalmo@yahoo.es

\section{Introduction}

Endometriosis is a chronic illness defined by the presence of functional endometrial tissue outside of the uterus. It affects $6-10 \%$ of women of reproductive age, $50-60 \%$ of women and adolescents with pelvic pain, and up to $50 \%$ of infertile women $[1,2]$. It is one of the pathologies that cause a large effect on the quality of life of young women, entailing a large social and economic impact on them and on the health care system [3].

Deep endometriosis is an aggressive form of endometriosis infiltrating more than $5 \mathrm{~mm}$ under the peritoneum. This term usually includes infiltrative forms involving structures such as bowel, ureters, bladder, and rectovaginal wall. Intestinal involvement occurs up to $12 \%$ of women with endometriosis, being its most common sites the rectosigmoid (65\%), the ileocecal (20\%) junctions, and the rectum $(15 \%)$ [4, 5]. Rectovaginal endometriosis (RVE) is characterized by its effect on the vagina, rectum, rectovaginal septum, Douglas pouch, and sometimes even the ureters [6-8]. The rectum is affected on its anterior wall and rarely the whole thickness of the intestinal wall [9].

Clinically, although it involves a benign process, RVE can alter the quality of life for patients due to dysmenorrhea, dyspareunia, limitation of sexual activity, and the severe dyschezia that are provoked [10]. Pharmacological treatment is not very effective for the majority of patients. Surgery is the best therapeutic option for symptomatic RVE, even though it implies a greater morbidity. Laparoscopy is the chosen approach [11-16].

The preoperative diagnosis for RVE is crucial in order to establish the precise distribution of the deeply infiltrating endometriotic lesions, which is the most relevant tool to help the surgeon decide how to treat these patients. 
Distinguishing retrocervical and rectovaginal involvement and the depth of lesions are important in the surgical management of patients. Clinical history, vaginal and rectal pelvic examination, transvaginal and transrectal ultrasounds, magnetic resonance imaging (MRI) and double-contrast barium enemas have been used for this purpose. Nevertheless, physical examination does not allow prediction of the extension of RVE, and the value of transvaginal sonography for assessment deep pelvic endometriosis is uncertain. Rectal endoscopic sonography has been recommended for detection of endometriosis in rectal, rectovaginal, uterosacral, or rectosigmoid locations, and MRI has demonstrated high sensitivity, specificity, positive and negative predictive values, and accuracy in prediction of the locations and in evaluation of the extension of lesions. The gold standard examination for classification of endometriosis is laparoscopy, and the diagnosis is confirmed by the histology obtained by laparoscopy or laparotomy or by the biopsy of visible endometriosic lesions in the posterior fornix [17-21]. The preoperative study should be done with an ultrasound of the urinary and kidney tracts, an intravenous pyelography to rule out an asymptomatic ureteral stenosis, and a rectosigmoidscopy to confirm the involvement of the rectal mucosa.

Several techniques have been proposed for the treatment of RVE with rectal involvement, with no consensus existing on which could be the best when the muscular rectal layer is affected [22]. In these cases, different surgical procedures have been described in terms of parameters, such as the size of the nodule and the affected bowel circumference, the depth of lesions on the rectal wall, the presence of other endometriosic foci, and the experience of the surgeon in the execution of each procedure $[23,24]$. The most common surgical procedures used in the treatment of RVE are superficial thickness excision (shaving), the resection of the nodule with excision of the anterior side of the rectum (full thickness discoid resection) and the colorectal segmental resection.

At present, some gynecological surgeons prefer colorectal resection for symptomatic patients, as they are convinced that resection of all intestinal endometriosic foci is the choice of treatment to improve pain and to avoid relapses [5, 13, 25-27]. On the other hand, other groups prefer the excision of the endometriosic nodule to colorectal resection, since the rate of morbidity is lower and the recurrence of pain is similar $[3,28-30]$.

Until now, there has not been a randomized study that compares the different techniques, and few review articles have been published in relation to surgical treatment of RVE. If we add to this the great variety of results from observational studies and the lack of clinical trials, a review of the medical literature published on this topic over the last 10 years is valuable. The main objective of our paper is to assess, standardize, and analyze the data and results obtained in different studies regarding the surgical techniques employed in the treatment of RVE with rectal involvement.

\section{Methods}

The review of medical literature was done through an electronic search for articles in the databases of the US National Library of Medicine (PubMed database) and the Cochrane Library (Cochrane database). Its objective was to identify all of the observational studies, clinical trials, systematic and nonsystematic reviews, and meta-analysis published in English between January of 2000 and June of 2010 regarding the surgical treatment of endometriosis of the rectovaginal septum. The medical terms combined in the search included RVE, deep endometriosis, deeply infiltrating endometriosis, surgical management, surgical treatment, surgery, and laparoscopy. The complete text was obtained for all the selected articles and the list of bibliographic references for each one was reviewed with the aim of identifying other studies that could also be included in our review. Summaries of congress communications and scientific meetings were not included in the selected literature.

Articles in press whose text and complete results were available at the time of our search were included. To be selected, the studies needed to have a series of characteristics that were considered inclusion criteria: Patients must be diagnosed with RVE by means of physical examination, vaginal or transrectal ultrasound, MRI, and biopsy with histological confirmation; analysis of the results of one or more surgical techniques performed as treatment for RVE must be performed. The initial selection of the papers was done independently by two authors (VP and $\mathrm{JJH})$ in terms of the title and abstract. In cases of discrepancy between the two authors, the decision to include or exclude the article was made by a third author (AP).

The year of publication, the type and design of the study, the number of patients, the surgical technique analyzed, and the primary and secondary results were taken from the selected papers. The studies were classified by their methodological design in observational studies, clinical trials, systematic and nonsystematic reviews, and meta-analysis. The two reviewers independently evaluated all the articles and produced a summary of each one according to a previously established format. The summaries were compiled into a single summary for each selected paper, reaching agreement by consensus in case of discrepancies.

This paper was not conceived as a systematic revision of the literature following QUOROM norms [31] since the different procedures described in the studies make it difficult to draw a direct comparison of the results. Moreover, the different papers do not provide results of 
the complications in detail or favorable effects of the surgery in terms of each technique. Therefore, we did not perform a qualitative analysis of the selected studies or a grouped analysis of the data obtained from them.

Forty one potentially relevant studies were identified. Of them, 36 corresponded to observational studies and five to nonsystematic revisions. No systematic revisions, clinical trials, or meta-analyses were identified.

\section{Findings}

The great heterogeneity of the studies in relation to the surgical treatment of RVE proves the difficulty of standardizing data collected and establishing general conclusions regarding the results. All of the analyzed studies are noncomparative observational studies with a limited number of patients. There were also five nonsystematic revisions published [3, 28, 32-34]. In some of the studies, a radical treatment was assessed $[5,13,15,25-27,40-56]$, while others assessed a conservative one [57-63]. There were six nonrandomized papers in which groups of patients with different therapeutic options were compared [30, 35-39]. The follow-up time was not uniform within studies, neither were the criteria used to establish the diagnosis, the extent of the RVE, or the result variables.

In relation to the type of surgical approach, two main groups can be observed: those who propose a more aggressive approach and tend to defend the systematic intestinal resection under the premise that a more radical approach would be more effective (segmental resection of the rectum and/or sigmoid colon) and those that argue for a more conservative approach basing their argument on the lack of scientific evidence of better results with more radical techniques and the association of these techniques with higher long-term morbidity and a lower quality of life for patients (shaving of the rectal wall, disc excision of the anterior rectal wall).

In this review, the studies are grouped according to the surgical approach evaluated: a radical approach, a conservative approach, or a comparative approach between different treatment methods.

\section{Radical surgery with intestinal resection}

Surgery for endometriosis of the rectovaginal septum was described for the first time in 1991 by Reich et al. [64]. Initially, the majority of papers defended a conservative surgical approach directed toward the extirpation or ablation of the endometriosic lesions with minimal excisional surgery of the rectum [6, 12, 65-68]. However, in the last decade, multiple authors have proposed more aggressive techniques including intestinal resection, especially in those cases with an affected muscularis propia of the rectum but also in those having an intact mucosa $[5,13,15,25-27,40-56]$. The argument used for the practice of this radical surgery is that of achieving the greatest resection possible of the endometriosic lesions, diminishing the postoperative symptomatology and avoiding any early relapse of the disease [41, 42].

Most of the studies summarized in our review consider complications, symptomatic improvement (dysmenorrhea, dyspareunia, chronic pelvic pain, and dyschezia), rate of recurrence, and postoperative indices of gestation as main outcomes. The results of these studies are shown in Table 1.

The largest casuistry of colorectal resections by laparoscopy with 436 cases was published this year by the group in Verona [56]. In this long series, the rate of complications in the immediate postoperative period was $10.7 \%$, with $3.2 \%$ being rectovaginal fistulas. In the later postoperative period, $9.5 \%$ of patients showed urinary retention and $4.2 \%$ constipation. The same authors published a previous report in 2009. In this publication, 357 cases were followed up for 20 months showing a recurrence rate of symptomatology of $6.3 \%$ and a recurrence rate of endometriosic nodules in $3.5 \%$ of the patients [27]. When they compared these results to those obtained after laparotomic colorectal resection, they found a similar rate of complications [51]. Keckstein and Weisinger [25] found a 7.4\% complications rate and Daraï et al. [26] reported a 10\% complications rate, with $6 \%$ being rectovaginal fistulas. When the laparotomic approach is used, Dousset et al. [5] reported a $16 \%$ complications rate, with $4 \%$ being rectovaginal fistulas. After 60 months follow-up, there were no relapses, but bladder and intestinal dysfunction reached $16 \%$ and $85 \%$, respectively.

In 2006, Landi et al. [20] studied 45 women and compared the results of segmental intestinal resection by laparoscopy in two groups of patients according to whether $(n=20)$ or not $(n=25)$ neural preservation was done. While the surgical complications were not statistically significant between the groups, a difference was noted in favor of the group doing neural preservation in terms of recuperation time for urinary function (3 days compared to 12.5 days) as well as the level of subjective satisfaction among the patients during the follow-up period.

In 2008, Zanetti-Dällenbach et al. [53] compared a new combined technique, vaginal-laparoscopic-abdominal, done on 30 patients compared to the 18 intestinal resections performed using traditional techniques. The authors describe fewer complications in the group using the combined technique (10\% vs. $39 \%)$ as well as lesser time of hospitalization (13.7 days compared to 15.8 days).

In 2009, Pereira et al. [54] analyzed the postoperative results of 168 women with RVE in which the intervention was conducted by gynecologists, without the initial 


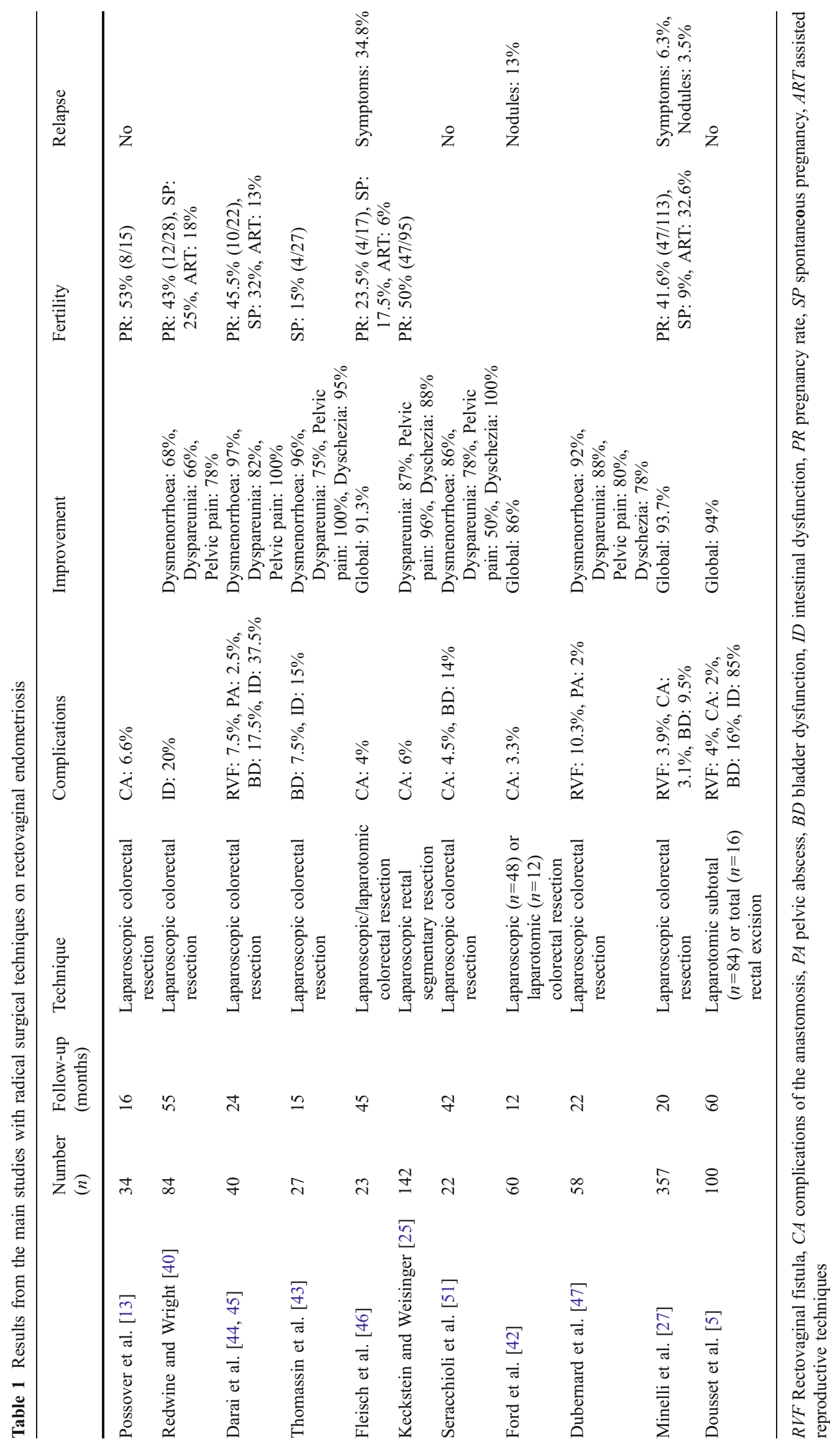


participation of colorectal surgeons. In these patients, the interventions included shaving resection, discoid resection, and segmental resection. The results were comparable to the studies in which the intervention of the intestine was done by a colorectal surgeon, with a percentage of global complications of $7.3 \%$ and a significant improvement in all the assessed clinical parameters. The authors conclude that, after adequate training, endometriosis with intestinal involvement could be treated safely and efficiently by gynecologists who specialized in pelvic surgery.

The most frequent complication of the radical colorectal surgery is bladder and intestinal dysfunction. The first is defined in the majority of the studies as persistent urinary retention 30 days after the intervention, in the context of the denervation of the inferior hypogastric plexus. In some studies, the proportion of patients affected by this side effect of the surgery reaches $16-17 \%[5,45]$. Intestinal dysfunction in these patients is defined by the existence of constipation or diarrhea during several weeks after the surgery, due to a mechanical effect by rectal reduction as well as a neural disorder because of the denervation of the rectal plexus. This is the most frequent complication, being 15 $20 \%$, although it can reach $85 \%$ in some $[5,40,45,49,56]$.

The second most frequent and very important complication due to its severity is the rectovaginal fistula, which reaches rates of $10 \%[45,47]$. Other complications that are normally described in these papers are related to alterations of rectal anastomosis and pelvic infectious processes (Table 1).

The indices of symptomatic improvement for patients treated with radical rectovaginal surgery in the majority of the analyzed studies stand around $90 \%$ as much in their global form as for each one of the assessed symptoms. This improvement is greater during the first year after the intervention, although it can stay above $70 \%$ of the patients after 3 and 5 years, especially for those specific intestinal symptoms such as dyschezia $[46,51]$.

In some reports, a subjective improvement is shown in the patients' global quality of life with respect to the time prior to the surgery $[42,45,47,48,50]$. Dubernard et al. [47] evaluated the quality of life in 58 women after laparoscopic colorectal resection using the validated questionnaire Medical Outcomes Study SF-36 and observed that all its items improved after surgery. Similar results were obtained by Ford et al. [42] in 60 patients following radical resection of RVE and by Lyons et al. [48] in seven patients undergoing laparoscopic colorectal surgery, both using the EQ-5D questionnaire.

Symptomatic recurrence was also analyzed by Fedele et al. [41] after following up 83 patients with RVE during 36 months. Thirty of them underwent laparotomic intestinal resection because of an involvement in the rectal wall. The rate of pain recurrence was $28 \%$, and the necessity for new intervention and/or medical treatment was $27 \%$. The factors which the authors correlated with a lessened probability of recurrence were pregnancy and intestinal resection. On the other hand, the youngest patients and those that had previously been treated for endometriosis showed a greater probability of recurrence. In the rest of the evaluated studies, the rate of relapse for the disease varies, ranging from some showing no reappearance of the disease to those that show 35\% 4 years after the intervention $[5,46]$.

In the studies in which reproductive results were analyzed, a general improvement was noted in their gestation rate after radical surgery [13, 40, 44]. This rate varied between the studies depending on the antecedents of sterility or the wish to gestate, standing around $50 \%$ in the majority of the patients. In some studies, no difference has been noted upon comparing the expectant attitude with the surgical technique [36]. Moreover, it is not specified in each series if the gestations were achieved spontaneously or after reproductive assistance treatment, making the interpretation of the results difficult. What does appear uniform between the papers is the conclusion that improvement of reproductive function after surgery for RVE is greater the younger the patient and the earlier the intervention is made $[44,45,55]$.

\section{Conservative surgery without intestinal resection}

The authors who propose conservative treatment of RVE point out as fundamental that it achieves lower indices of complications and similar rates of symptomatic improvement and preservation of fertility when compared with intestinal resection [68].

The most frequent conservative surgical techniques in the treatment of RVE are those aiming for simple lesional resection after separating the endometriosic nodule from the rectal wall [57], layer-to-layer excision shaving of the lesion without resecting the entire thickness of the intestinal wall [63], and discoidal resection with complete excision of the affected area of the intestinal wall by the endometriosic nodule [35]. In addition, in some papers, the technique proposed was in-block excision of the posterior vaginal fornix in an attempt as much to eliminate the greatest possible part of the disease as to avoid its progression $[58,60,61]$. This same proposal was done by Matsuzaki et al. [62] by studying histological samples from 61 patients after in-block resection for RVE. Every single sample was infiltrated by endometriosic tissue.

The main results of the papers, which assessed the conservative surgery for ERV, are shown in Table 2.

The largest casuistry using a conservative approach (the shaving technique) is that recently published by Donnez and Squifflet [63] with 500 cases. In this study, the rate of serious complications was $3.2 \%$, the rate of relapse was 
$8 \%$, and $84 \%$ of women gestated after the intervention, $57 \%$ spontaneously. With this technique, there were no functional alterations of the bladder or intestine 1 month after the intervention.

The effectiveness of the discoidal resection technique was put in doubt by Remorgida et al. [59]. A segmental intestinal resection was done systematically after discoidal resection. The histological study of the enlarged piece, a priori free from disease, revealed that. in 7 of the 16 cases (43.8\%), endometriosic tissue could still be found infiltrating up to the muscular intestinal layer, with a maximum distance of $2.6 \mathrm{~cm}$ from the edge of the nodulectomy, although other studies demonstrate that intestinal resection does not guarantee the complete elimination of endometriosic foci either $[69,70]$.

The in-block excision techniques of the posterior vaginal fornix are accompanied by resection of the endometriosic nodule and, as what happens with these techniques, there are low rates of complications and high rates of pain improvement $[58,60,61]$. In terms of fertility, the indices of gestation were $57 \%$ [58].

\section{Comparative studies}

Few studies have been published up until now comparing groups of patients with RVE treated with different therapeutic attitudes. All of them are observational studies in which the treatment option was not decided randomly; rather, it was made in terms of clinical criteria or in consensus with the patients [30, 35-39].

In four of these studies [30, 35, 37, 39], they compared the postoperative results between different techniques used for RVE. Although some of the outcomes and the way they were assessed are not directly comparable between papers, one can see a tendency that points to a similar symptomatic improvement among the different techniques and a greater rate of surgical complications among the most radical approaches.

The results for discoidal resection analyzed in comparative studies (Table 3) show that the rate of severe complications remains low, the symptomatic improvement stands around $90 \%$, and the rate of relapse between $5 \%$ and $14 \%[30,35$, 37, 39]. Gestation rates, though low as they are, are still higher than those obtained with radical treatments [37, 39].

Fanfani et al. [39] compared two groups of symptomatic patients, with nodules smaller than $3 \mathrm{~cm}$ and stenosis of the intestinal lumen less than $60 \%$, and observed that the group of 48 patients treated conservatively by laparoscopic discoidal resection showed less postoperative morbidity and similar rates of relapse when compared with the group of 88 patients treated via laparoscopic segmental intestinal resection. In another study, Roman et al. [30] achieved a 
Table 3 Results of comparative studies between different surgical techniques for rectovaginal endometriosis

\begin{tabular}{|c|c|c|c|c|c|}
\hline & & $\begin{array}{l}\text { Mohr et al. [35] } \\
\text { (24 months) }\end{array}$ & $\begin{array}{l}\text { Brouwer and Woods [37] } \\
\text { (68 months) }\end{array}$ & $\begin{array}{l}\text { Fanfani et al. [39] } \\
\text { (32 months) }\end{array}$ & $\begin{array}{l}\text { Roman et al. [30] } \\
\text { (26 months) }\end{array}$ \\
\hline \multirow[t]{5}{*}{ Shaving } & Number $(n)$ & 100 & 18 & & \\
\hline & Complications & Total: $6 \%$ & Total: $17 \%$, PA: $5.6 \%$ & & \\
\hline & Improvement & $80 \%$ & & & \\
\hline & Relapse & & $22.2 \%$ & & \\
\hline & Fertility & $17 \%$ & & & \\
\hline \multirow[t]{5}{*}{ Discoidal excision } & Number $(n)$ & 39 & 58 & 48 & 16 \\
\hline & Complications & $\begin{array}{l}\text { Total: } 23 \% \text {, } \\
\text { RVF: } 3 \% \text {, PA: } 5 \%\end{array}$ & Total: $2 \%, \mathrm{CA}: 2 \%$ & $\begin{array}{c}\text { Total: } 31.4 \% \text {, RVF: } 2.1 \% \text {, } \\
\text { PA: } 2.1 \% \text {, ID: } 2.1 \%\end{array}$ & ID: $19 \%$ \\
\hline & Improvement & $92 \%$ & & $88.8 \%$ & $86 \%$ \\
\hline & Relapse & & $5.17 \%$ & $13.8 \%$ & \\
\hline & Fertility & $11 \%$ & & & $13 \%$ \\
\hline \multirow{5}{*}{$\begin{array}{l}\text { Segmental intetinal } \\
\text { resection }\end{array}$} & Number $(n)$ & 48 & 137 & 88 & 25 \\
\hline & Complications & $\begin{array}{l}\text { Total: } 38 \%, \\
\text { BD: } 2 \%, \text { CA: } 6 \%\end{array}$ & $\begin{array}{l}\text { Total: } 8 \% \text {, PA: } 1.4 \% \text {, CA: } \\
2.2 \% \text {, BD: } 1.4 \% \text {, ID: } 9 \%\end{array}$ & $\begin{array}{l}\text { Total: } 59.7 \% \text {, RVF: } 3.4 \% \text {, } \\
\text { PA: } 2.2 \% \text {, BD: } 14.7 \% \text {, } \\
\text { CA: } 1.1 \% \text {, ID: } 4.5 \%\end{array}$ & BD: $8 \%$, ID: $64 \%$ \\
\hline & Improvement & $92 \%$ & & $93 \%$ & $83 \%$ \\
\hline & Relapse & & $2.19 \%$ & $11.5 \%$ & \\
\hline & Fertility & $3 \%$ & & & $12 \%$ \\
\hline
\end{tabular}

$R V F$ Rectovaginal fistula, $C A$ complications of the anastomosis, $P A$ pelvic abscess, $B D$ bladder dysfunction, $I D$ intestinal dysfunction

lesser rate of urinary and intestinal disorders after discoidal resection even when they did not set up any nodule size limit.

Vercellini et al. [36] compared the effect of conservative nodulectomy through laparotomy and the expectant attitude in 44 and 61 infertile patients with RVE respectively, affirming that this type of surgery does not modify the reproductive outcome compared to the expectant attitude.

\section{Conclusions}

Endometriosis generally affects otherwise healthy young women with high expectations of well-being and quality of life. In this population, complications and side effects of surgery are tolerated with difficulty, and the recurrence of symptoms can be especially frustrating. In addition, the case of RVE is a complex pathology with difficult treatment, so that a careful and individualized evaluation in consensus with the patient must be taken into account at the time of choosing any surgical technique so that there is a balance between the expected benefit and the morbidity related to each technique. Surgical treatment of this form of endometriosis is necessary when the disease causes a reduction in the patients' quality of life, given that, in general, patients without symptoms will benefit from an expectant therapeutic attitude.

Laparoscopic treatment of RVE with rectal affectation through discoidal or segmental resection is safe and feasible, achieving similar or better results than laparotomic surgery $[16,27]$. When surgical treatment does not include intestinal resection, the rates of surgical complications are low, in the majority of papers not reaching $5 \%$, with bladder and intestinal dysfunction practically nonexistent. This lower morbidity is not accompanied by a greater rate of relapse [39]; therefore, colorectal resections should be reserved for those cases where the nodule is so large that it makes the suture of the intestine technically impossible or when the patient would like to gestate immediately, ruling out prolonged hormonal treatments [30].

Unanimity exists in that the preoperative symptoms as well as the quality of the patients' lives improve significantly in the years after RVE surgery. This improvement stands above $90 \%$ of patients, fundamentally with relation to pain symptoms (dysmenorrhoea, dyspareunia, dyschezia, and chronic pelvic pain), with no significant difference between resection surgery and conservative surgery.

Although the studies published to this point to assess the effect of different surgical techniques on the treatment of RVE show a great heterogeneity in their characteristics and methodology, we can say that, whenever technically possible, the more conservative techniques, shaving and discoidal intestinal resection, would be recommended since they present a lower rate of complications with similar recurrence and greater rates of gestation. Nevertheless, it would be worthwhile to develop randomized trials with a greater number of patients with longer-term follow-up to compare the results of intestinal resection and conservative treatment of rectovaginal endometriosis. 
Conflicts of interest None.

\section{References}

1. Kennedy S, Bergquist A, Chapron C, D'Hooghe T, Dunselman G, Greb R et al (2005) ESHRE guideline for the diagnosis and treatment of endometriosis. Hum Reprod 20:2698-2704

2. Giudice LC (2010) Endometriosis. N Engl J Med 362:2389-2398

3. Vercellini P, Crosignani PG, Abbiati A, Somigliana E, Vigano P, Fedele L (2009) The effect of surgery for symptomatic endometriosis: the other side of the story. Hum Reprod Update 15:177-188

4. Bergqvist A (1993) Different types of extragenital endometriosis: a review. Gynecol Endocrinol 7:207-221

5. Dousset B, Leconte M, MD BB, Millischer AE, Roseau G, Arkwright S, Chapron C (2010) Complete surgery for low rectal endometriosis. Long-term results of a 100-case prospective study. Ann Surg 251:887-895

6. Koninckx PR, Timmermans B, Meuleman C, Penninckx F (1996) Complications of CO2-laser endoscopic excision of deep endometriosis. Hum Reprod 11:2263-2268

7. Martin DC, Batt RE (2001) Retrocervical, rectovaginal pouch, and rectovaginal septum endometriosis. J Am Assoc Gynecol Laparosc $8: 12-17$

8. Donnez J, Nisolle M, Squifflet J (2002) Ureteral endometriosis: a complication of rectovaginal endometriotic (adenomyotic) nodules. Fertil Steril 77:32-37

9. Chapron C, Fauconnier A, Dubuisson JB, Barakat H, Vieira M, Bréart G (2003) Deep infiltrating endometriosis: relation between severity of dysmenorrhoea and extent of disease. Hum Reprod 18:760-766

10. Vercellini P, Crosignani PG, Somigliana E, Berlanda N, Barbara G, Fedele L (2009) Medical treatment for rectovaginal endometriosis: what is the evidence? Hum Reprod 24:2504-2514

11. Redwine DB, Sharpe DR (1991) Laparoscopic segmental resection of the sigmoid colon for endometriosis. J Laparoendosc Surg $1: 217-220$

12. Nezhat C, Nezhat F, Pennington E (1992) Laparoscopic treatment of infiltrative rectosigmoid colon and rectovaginal septum endometriosis by the technique of videolaparoscopy and the CO2 laser. Br J Obstet Gynaecol 99:664-667

13. Possover M, Diebolder H, Paul K, Schneider A (2000) Laparoscopically assisted vaginal resection of rectovaginal endometriosis. Obstet Gynecol 96:304-307

14. Duepree HJ, Senagore AJ, Delaney CP, Marcello PW, Brady KM, Falcone T (2002) Laparoscopic resection of deep pelvic endometriosis with rectosigmoid involvement. J Am Coll Surg 195:754758

15. Landi S, Ceccaroni M, Perutelli A, Allodi C, Barbieri F, Fiaccavento A, Ruffo G, McVeigh E, Zanolla L, Minelli L (2006) Laparoscopic nerve-sparing complete excision of deep endometriosis: is it feasible? Hum Reprod 21:774-781

16. Daraï E, Dubernard G, Coutant C, Frey C, Rouzier R, Ballester M (2010) Randomized trial of laparoscopically assisted versus open colorectal resection for endometriosis: morbidity, symptoms, quality of life, and fertility. Ann Surg 251:1018-1023

17. Fedele L, Bianchi S, Portuese A, Borruto F, Dorta M (1998) Transrectal ultrasonography in the assessment of rectovaginal endometriosis. Obstet Gynecol 91:444-448

18. Goncalves MO, Podgaec S, Dias JA Jr, Gonzalez M, Abrao MS (2010) Transvaginal ultrasonography with bowel preparation is able to predict the number of lesions and rectosigmoid layers affected in cases of deep endometriosis, defining surgical strategy. Hum Reprod 25:665-671
19. Kinkel K, Chapron C, Balleyguier C, Fritel X, Dubuisson JB, Moreau JF (1999) Magnetic resonante imaging characteristics of deep endometriosis. Hum Reprod 14:1080-1086

20. Landi S, Barbieri F, Fiaccavento A, Mainardi P, Ruffo G, Selvaggi L, Syed R, Minelli L (2004) Preoperative double-contrast barium enema in patients with suspected intestinal endometriosis. J Am Assoc Gynecol Laparosc 11:223-228

21. Del Frate C, Girometti R, Pittino M, Del Frate G, Bazzocchi M, Zuiani C (2006) Deep retroperitoneal pelvic endometriosis: MR imaging appearance with laparoscopic correlation. Radiographics $26: 1705-1718$

22. CNGOF Guidelines for the Management of Endometriosis Collège National des Gynécologues et Obstétriciens Français, 2006. http://www.cngof.asso.fr/D TELE/RPC endometriose en BM.pdf

23. Chapron C, Chopin N, Borghese B, Foulot H, Dousset B, VacherLavenu MC et al (2006) Deeply infiltrating endometriosis: pathogenetic implications of the anatomical distribution. Hum Reprod 21:1839-1845

24. Abrao MS, Podgaec S, Dias JA, Averbach M, Silva LF, Marino de Carvalho F (2008) Endometriosis lesions that compromise the rectum deeper than the inner muscularis layer have more than $40 \%$ of the circumference of the rectum affected by the disease. $\mathrm{J}$ Minim Invasive Gynecol 15:280-285

25. Keckstein J, Wiesinger H (2005) Deep endometriosis, including intestinal involvement - the interdisciplinary approach. Minim Invasive Ther Allied Technol 14:160-166

26. Daraï E, Bazot M, Rouzier R, Houry S, Dubernard G (2007) Outcome of laparoscopic colorectal resection for endometriosis. Curr Opin Obstet Gynecol 19:308-313

27. Minelli L, Fanfani F, Fagotti A, Ruffo G, Ceccaroni M, Mereu L, Landi S, Pomini P, Scambia G (2009) Laparoscopic colorectal resection for bowel endometriosis: feasibility, complications, and clinical outcome. Arch Surg 144:234-239

28. Donnez J, Squifflet J (2004) Laparoscopic excision of deep endometriosis. Obstet Gynecol Clin N Am 31:567-580

29. Ret Davalos ML, De Cicco C, D'Hoore A, De Decker B, Koninckx PR (2007) Outcome after rectum or sigmoid resection: a review for gynecologists. J Minim Invasive Gynecol 14:33-38

30. Roman H, Loisel C, Resch B, Tuech JJ, Hochain P, Leroi AM, Marpeau L (2010) Delayed functional outcomes associated with surgical management of deep rectovaginal endometriosis with rectal involvement: giving patients an informed choice. Hum Reprod 25:890-899

31. Moher D, Cook DJ, Eastwood S, Olkin I, Rennie D, Stroup DF (1999) Improving the quality of reports of meta-analyses of randomised controlled trials: the QUOROM statement. Quality of reporting of meta-analyses. Lancet 354:1896-1900

32. Koh CH, Janik GM (2002) The surgical management of deep rectovaginal endometriosis. Curr Opin Obstet Gynecol 14:357-364

33. Emmanuel KR, Davis C (2005) Outcomes and treatment options in rectovaginal endometriosis. Curr Opin Obstet Gynecol 17:399-402

34. Vercellini P, Barbara G, Abbiati A, Somigliana E, Viganò P, Fedele L (2009) Repetitive surgery for recurrent symptomatic endometriosis: what to do? Eur J Obstet Gynecol Reprod Biol 146:15-21

35. Mohr C, Nezhat FR, Nezhat CH, Seidman DS, Nezhat CR (2005) Fertility considerations in laparoscopic treatment of infiltrative bowel endometriosis. JSLS 9:16-24

36. Vercellini P, Pietropaolo G, De Giorgi O, Daguati R, Pasin R, Crosignani PG (2006) Reproductive performance in infertile women with rectovaginal endometriosis: is surgery worthwhile? Am J Obstet Gynecol 195:1303-1310

37. Brouwer R, Woods RJ (2007) Rectal endometriosis: results of radical excision and review of published work. ANZ J Surg $77: 562-571$ 
38. Maytham GD, Dowson HM, Levy B, Kent A, Rockall TA (2009) Laparoscopic excision of rectovaginal endometriosis: report of a prospective study and review of the literature. Colorectal Dis Jul 3 (Epub ahead of print)

39. Fanfani F, Fagotti A, Gagliardi ML, Ruffo G, Ceccaroni M, Scanbia G, Minelli L (2010) Discoid or segmental rectosigmoid resection for deep infiltrating endometriosis: a case-control study. Fertil Steril 94:444-449

40. Redwine DB, Wright JT (2001) Laparoscopic treatment of complete obliteration of the cul-de-sac associated with endometriosis: long-term follow-up of en bloc resection. Fertil Steril 76:358-365

41. Fedele L, Bianchi S, Zanconato G, Bettoni G, Gotsch F (2004) Long term follow up after conservative surgery for rectovaginal endometriosis. Am J Obstet Gynecol 190:1020-1024

42. Ford J, English J, Miles WA, Giannopoulos T (2004) Pain, quality of life and complications following the radical resection of rectovaginal endometriosis. BJOG 111:353-356

43. Thomassin I, Bazot M, Detchev R, Barranger E, Cortez A, Darai E (2004) Symptoms before and after surgical removal of colorectal endometriosis that are assessed by magnetic resonance imaging and rectal endoscopic sonography. Am J Obstet Gynecol 190:1264-1271

44. Darai E, Marpeau O, Thomassin I, Dubernard G, Barranger E, Bazot M (2005) Fertility after laparoscopic colorectal resection for endometriosis: preliminary results. Fertil Steril 84:945-950

45. Darai E, Thomassin I, Barranger E, Detchev R, Cortez A, Houry S, Bazot M (2005) Feasibility and clinical outcome of laparoscopic colorectal resection for endometriosis. Am J Obstet Gynecol 192:394-400

46. Fleisch MC, Xafis D, De Bruyne F, Hucke J, Bender HG, Dall P (2005) Radical resection of invasive endometriosis with bowel or bladder involvement-long-term results. Eur J Obstet Gynecol Reprod Biol 123:224-229

47. Dubernard G, Piketty M, Rouzier R, Houry S, Bazot M, Darai E (2006) Quality of life after laparoscopic colorectal resection for endometriosis. Hum Reprod 21:1243-1247

48. Lyons SD, Chew SS, Thomson AJ, Lenart M, Camaris C, Vancaillie TG et al (2006) Clinical and quality-of-life outcomes after fertility-sparing laparoscopic surgery with bowel resection for severe endometriosis. J Minim Invasive Gynecol 13:436-441

49. Ribeiro PA, Rodrigues FC, Kehdi IP, Rossini L, Abdalla HS, Donadio $\mathrm{N}$ et al (2006) Laparoscopic resection of intestinal endometriosis: a 5-year experience. J Minim Invasive Gynecol 13:442-446

50. Langebrekke A, Istre O, Busund B, Johannessen HO, Qvigstad E (2006) Endoscopic treatment of deep infiltrating endometriosis (DIE) involving the bladder and rectosigmoid colon. Acta Obstet Gynecol Scand 85:712-715

51. Seracchioli R, Poggioli G, Pierangeli F, Manuzzi L, Gualerzi B, Savelli L et al (2007) Surgical outcome and long-term follow up after laparoscopic rectosigmoid resection in women with deep infiltrating endometriosis. BJOG 114:889-895

52. Mereu L, Ruffo G, Landi S, Barbieri F, Zaccoletti R, Fiaccavento A et al (2007) Laparoscopic treatment of deep endometriosis with segmental colorectal resection: short-term morbidity. J Minim Invasive Gynecol 14:463-469

53. Zanetti-Dällenbach R, Bartley J, Müller C, Schneider A, Köhler C (2008) Combined vaginal-laparoscopic-abdominal approach for the surgical treatment of rectovaginal endometriosis with bowel resection: a comparison of this new technique with various established approaches by laparoscopy and laparotomy. Surg Endosc 22:995-1001
54. Pereira RM, Zanatta A, Preti CD, de Paula FJ, da Motta EL, Serafini PC (2009) Should the gynecologist perform laparoscopic bowel resection to treat endometriosis? Results over 7 years in 168 patients. J Minim Invasive Gynecol 16:472-479

55. Stepniewska A, Pomini P, Scioscia M, Mereu L, Ruffo G, Minelli L (2010) Fertility and clinical outcome after bowel resection in infertile women with endometriosis. Reprod Biomed Online 20:602-609

56. Ruffo G, Scopelliti F, Scioscia M, Ceccaroni M, Mainardi P, Minelli L (2010) Laparoscopic colorectal resection for deep infiltrating endometriosis: analysis of 436 cases. Surg Endosc 24:63-67

57. Chapron C, Jacob S, Dubuisson JB, Vieira M, Liaras E, Fauconnier A (2001) Laparoscopically assisted vaginal management of deep endometriosis infiltrating the rectovaginal septum. Acta Obstet Gynecol Scand 80:349-354

58. Hollett-Caines J, Vilos GA, Penava DA (2003) Laparoscopic mobilization of the rectosigmoid and excision of the obliterated cul-de-sac. J Am Assoc Gynecol Laparosc 10:190-194

59. Remorgida V, Ragni N, Ferrero S, Anserini P, Torelli P, Fulcheri E (2005) How complete is full thickness disc resection of bowel endometriotic lesions? A prospective surgical and histological study. Hum Reprod 20:2317-2320

60. Angioni S, Peiretti M, Zirone M, Palomba M, Mais V, Gomel V et al (2006) Laparoscopic excision of posterior vaginal fornix in the treatment of patients with deep endometriosis without rectum involvement: surgical treatment and long-term follow-up. Hum Reprod 21:1629-1634

61. Kristensen J, Kjer JJ (2007) Laparoscopic laser resection of rectovaginal pouch and rectovaginal septum endometriosis: the impact on pelvic pain and quality of life. Acta Obstet Gynecol Scand 86:1467-1471

62. Matsuzaki S, Houlle C, Botchorishvili R, Pouly JL, Mage G, Canis M (2009) Excision of the posterior vaginal fornix is necessary to ensure complete resection of rectovaginal endometriotic nodules of more than $2 \mathrm{~cm}$ in size. Fertil Steril 91(4 Suppl):1314-1315

63. Donnez J, Squifflet J (2010) Complications, pregnancy and recurrence in a prospective series of 500 patients operated on by the shaving technique for deep rectovaginal endometriotic nodules. Hum Reprod 25:1949-1958

64. Reich H, McGlynn F, Salvat J (1991) Laparoscopic treatment of cul-de-sac obliteration secondary to retrocervical deep fibrotic endometriosis. J Reprod Med 36:516-522

65. Donnez J, Nisolle M, Casanas-Roux F, Bassil S, Anaf V (1995) Rectovaginal septum, endometriosis or adenomyosis: laparoscopic management in a series of 231 patients. Hum Reprod 10:630-635

66. Crosignani PG, Vercellini P, Biffignandi F, Costantini W, Cortesi I, Imparato E (1996) Laparoscopy versus laparotomy in conservative surgical treatment for severe endometriosis. Fertil Steril $66: 706-711$

67. Donnez J, Nisolle M, Gillerot S, Smets M, Bassil S, Casanas-Roux F (1997) Rectovaginal septum adenomyotic nodules: a series of 500 cases. Br J Obstet Gynaecol 104:1014-1018

68. Bailey HR (1992) Colorectal endometriosis. Perspect Colon Rectal Surg 5:251-259

69. Roman H, Puscasiu L, Kouteich K, Gromez A, Resch B, Marouteau-Pasquier N, Hochain P, Tuech JJ, Scotte M, Marpeau L (2007) Laparoscopic management of deep endometriosis with rectal affect. Chirurgia 102:421-428

70. Anaf V, El Nakadi I, De Moor V, Coppens E, Zalcman M, Noel JC (2009) Anatomic significance of a positive barium enema in deep infiltrating endometriosis of the large bowel. World J Surg $33: 822-827$ 